\title{
Associated autoimmune diseases in patients with multifocal motor neuropathy and their family members
}

\author{
Elisabeth A. Cats • Anne Suzanne Bertens • \\ Jan H. Veldink • Leonard H. van den Berg • \\ W. Ludo van der Pol
}

Received: 7 September 2011/Revised: 6 October 2011/Accepted: 3 November 2011/Published online: 23 November 2011

(C) The Author(s) 2011. This article is published with open access at Springerlink.com

\begin{abstract}
Multifocal motor neuropathy (MMN) is a rare immune-mediated disorder and is characterized by male predominance, the presence of serum anti-GM1 IgM antibodies in up to half of all patients, responsiveness to intravenous immunoglobulins (IVIg) and an increased frequency of HLA type HLA-DRB $1 * 15$. The aim of this study was to assess whether the frequency of autoimmune diseases (AID) is increased in patients with MMN and their first-degree family members, since this would indicate that MMN shares pathogenic mechanisms with other AID. We conducted a case-control study using questionnaires to evaluate the prevalence of AID in MMN and controls, and their first-degree relatives. Questionnaires from $81 \mathrm{MMN}$ patients (417 first-degree relatives) and 438 controls (2,377 first-degree relatives) were analyzed. Overall prevalence of AID was higher in MMN patients $(11 \%)$ than in controls (5\%) (OR 2.4, 95\% CI 1.1-5.5, $p=0.037$ ). Type 1 diabetes, Hashimoto's thyroid disease, and celiac disease were significantly more prevalent in family members of patients than controls. The presence of an additional AID was not associated with age at MMN onset, disease duration, titer of serum anti-GM1 IgM antibodies or HLA type HLADRB1*15. The higher frequency of AID in patients with MMN indicates a common autoimmune diathesis.
\end{abstract}

Keywords Autoimmune diseases - Multifocal motor neuropathy

E. A. Cats and A. S. Bertens contributed equally.

E. A. Cats $(\bowtie)$ - A. S. Bertens · J. H. Veldink ·

L. H. van den Berg . W. L. van der Pol

Department of Neurology, Rudolf Magnus Institute

of Neuroscience, University Medical Centre Utrecht,

Heidelberglaan 100, 3584 CX Utrecht, The Netherlands

e-mail: e.cats@umcutrecht.nl

\section{Introduction}

Multifocal motor neuropathy (MMN) is an immune-mediated chronic asymmetrical motor neuropathy [11, 12]. More than $90 \%$ of patients with MMN respond favourably to treatment with intravenous immunoglobulins (IVIg) and sera of up to $50 \%$ of patients with MMN contain IgM antibodies against the ganglioside GM1 [6], which is highly expressed in motor nerves [19]. MMN aetiology has not been fully elucidated. Anti-GM1 IgM antibodies probably play a pathogenic role in MMN [5]. We recently reported an association of MMN with HLA DRB1*15, which might indicate that MMN shares pathogenetic pathways with other autoimmune diseases (AID) [15]. AID tend to cluster in relatives of patients with neurological AID such as multiple sclerosis (MS), the Lambert-Eaton myasthenic syndrome (LEMS), and myasthenia gravis (MG) $[4,8,20]$. To assess whether patients with MMN share a common autoimmune diathesis we conducted a case-control study using questionnaires to compare frequencies of AID in controls and MMN patients, and their first-degree relatives.

\section{Materials and methods}

The cases were patients with MMN who participated in a national cross-sectional study on MMN conducted in the Netherlands from January until December 2007 [6]. Inclusion criteria were diagnoses of definite, probable or possible MMN according to criteria published previously [17]. All MMN patients were approached by telephone and asked to complete a postal questionnaire. Non-responders were again contacted by telephone after 3 months.

Six hundred and fifty population-based controls from a control database were approached by mail and asked to 
complete and return the postal questionnaire [18]. People who returned incomplete questionnaires were contacted by telephone in order to complete the data.

The questionnaire was designed to document gender, date of birth and family history regarding first-degree relatives (parents, siblings), and the presence of the 18 most prevalent AID in the Netherlands according to the data collected by the Dutch Central Bureau for Statistics.

For each specific disease a description in layman's terms was provided and subjects were asked whether they or their parents or siblings (living and deceased) had any of the AID listed. Additional questions were asked if patients or controls reported any of the following three AID: (1) for type 1 diabetes, age at disease onset and use of insulin were used to differentiate type 1 from type 2 diabetes [1]. (2) Since previous studies showed that the presence of rheumatoid arthritis (RA) tended to be over-reported in a comparable study design [4], subjects were asked if the affected individuals were being treated by a rheumatologist to differentiate between actual RA and other, non-AID with affected joints such as osteoarthritis. (3) To differentiate between pernicious anaemia and other forms of anaemia, subjects were asked if the affected individuals were or had been treated with vitamin B12 injections.

Two diseases other than AID, myocardial infarction and asthma, were included in the questionnaire to control for reporting bias. These diseases have a high prevalence in the general population and no suspected relation with MMN or AID in general.

Both patients and controls who reported the presence of AID were contacted by phone and by a medical doctor to ensure the validity of the diagnosis.

The Medical Ethical Committee of the University Medical Center (UMC) Utrecht approved the study and the study was therefore performed in accordance with the ethical standards laid down in the 1964 Declaration of Helsinki. All participants gave written informed consent prior to the study.

Prevalence of AID in patients and controls, as well as in families, was analysed with logistic regression analysis and adjusted for age. Differences between patients with and patients without an AID were tested using the Mann-Whitney $U$ test and the $\chi^{2}$ or Fisher's exact test when appropriate.

\section{Results}

Eighty-eight MMN patients [6] and 600 potential controls were asked to participate in this study and were approached by mail. Questionnaires of $81 \mathrm{MMN}$ patients (response rate $92 \%$ ) and 438 (response rate $73 \%$ ) controls were returned. In total, 2,794 relatives of 519 index cases and controls were included in this survey.
Characteristics of MMN patients and controls

Characteristics of MMN patients and controls are summarized in Table 1. The median duration of MMN at inclusion was 14 years (range 1-46 years) and the median age at onset of disease was 41 years (range 22-66 years). The control group $(n=438)$ included 108 women $(25 \%)$, a percentage comparable to the patient group, but the median age at inclusion was higher in controls $(p=0.004)$. We adjusted for the difference in age in the statistical analysis.

\section{AID in MMN patients and controls}

Table 2 summarizes the prevalence of specific AID in MMN patients and controls. Nine MMN patients (11\%) had one or more of the listed AID. One MMN patient (1.2\%) had two of the listed AID: Crohn's disease and ankylosing spondylitis; the other eight MMN patients (9.9\%) had one of the listed AID. The presence of AID was not associated with patient characteristics including age at MMN onset, disease duration, maintenance treatment with IVIg, muscle strength, presence and titer of serum antiGM1 IgM antibodies, or the presence of HLA type HLADRB1*15. Two MMN patients had celiac disease. Serum of one of these patients contained anti-GM1 IgM antibodies (titer 1:400) but no other anti-ganglioside antibodies. Twenty-two of 438 controls (5\%) had one or more of the listed AID. Four controls $(0.9 \%)$ had more than one AID (psoriasis and RA; Graves' hyperthyroidism and RA; MG and RA; psoriasis and Hashimoto's thyroid disease).

Prevalence of AID was higher in MMN patients compared to controls [odds ratio (OR) 2.4, 95\% confidence interval (CI) $1.1-5.5, p=0.037]$. Females were more affected by AID compared to males: $50 \%$ of affected subjects in MMN patients were females $\left(\chi^{2} p=0.02\right)$ and $41 \%$ of affected indices in controls were females $\left(\chi^{2}\right.$ $p=0.07)$ while the total percentage of females in both groups was $25 \%$ (Table 1). Celiac disease (two MMN patients), Crohn's disease (one patient), ankylosing

Table 1 Characteristics of MMN patients and controls

\begin{tabular}{lcc}
\hline & Patients & Controls \\
\hline $\begin{array}{l}\text { Total number of indices } \\
\begin{array}{l}\text { Number of affected indices } \\
(\% \text { of total) }\end{array}\end{array}$ & 91 & 438 \\
$\begin{array}{l}\text { Number of females (\% of total) } \\
\text { Number of females in } \\
\text { affected indices (\% of total) }\end{array}$ & $20(25 \%)$ & $108(25 \%)$ \\
$\begin{array}{l}\text { Age (years) at inclusion } \\
\text { (median, range) }\end{array}$ & $5(56 \%)$ & $9(41 \%)$ \\
$\begin{array}{l}\text { Age (years) at inclusion of affected } \\
\text { indices (median, range) }\end{array}$ & $49(41-67)$ & $54(46-77)$ \\
\hline
\end{tabular}


Table 2 Prevalence of autoimmune diseases in MMN patients and controls

\begin{tabular}{lll}
\hline Disease & $\begin{array}{l}\text { Prevalence }(\%) \\
\text { MMN patients } \\
(n=81)\end{array}$ & $\begin{array}{l}\text { Prevalence }(\%) \\
\text { controls } \\
(n=438)\end{array}$ \\
\hline Diabetes type 1 & 0 & 0 \\
Graves' hyperthyroidism & 0 & 0.9 \\
Hashimoto's thyroid disease & 1.2 & 0.7 \\
Addison's disease & 0 & 0 \\
Rheumatoid arthritis & 0 & 1.8 \\
Ankylosing spondylitis & 1.2 & 0 \\
Systemic lupus erythematosus & 0 & 0 \\
Cutaneous lupus erythematosus & 1.2 & 0 \\
Sjögren's syndrome & 0 & 0 \\
Myasthenia gravis & 0 & 0.2 \\
Multiple sclerosis & 0 & 0 \\
Dermatomyositis & 1.2 & 0 \\
Psoriasis & 2.5 & 1.1 \\
Vitiligo & 1.2 & 0.7 \\
Crohn's disease & 1.2 & 0 \\
Ulcerative colitis & 0 & 0.2 \\
Celiac disease & 2.5 & 0 \\
Pernicious anaemia & 0 & 0.2 \\
\hline
\end{tabular}

spondylitis (one MMN patient) and cutaneous lupus erythematosus (one MMN patient) were exclusively observed in MMN patients but not in controls.

\section{AID in case and control families}

Table 3 summarizes the prevalence of AID in relatives of MMN patients and controls. Twenty-eight out of 417 family members of patients with MMN had an AID (6.7\%), whereas 157 out of 2,377 relatives from controls had an AID (6.6\%) (OR 1.0, 95\% CI 0.7-1.6; $p=0.93$ ). Type 1 diabetes, Hashimoto's thyroid disease, and celiac disease were significantly more prevalent in family members of patients than of controls. To exclude reporting bias, patients and controls were asked whether they or family members had asthma or had experienced myocardial infarction. There was no significant difference in prevalence of asthma (patients $4.9 \%$, controls $6.4 \%, p=0.71$; relatives of patients $2.1 \%$, relatives of controls $2.4 \%$, $p=0.73$ ) or myocardial infarction (patients $1.2 \%$, controls $4.7 \%, p=0.33$; relatives of patients $6.5 \%$, relatives of controls $9.1 \%, p=0.08$ ).

\section{Discussion}

This study shows that AID may occur more frequently in patients with MMN compared to controls. This suggests
Table 3 Prevalence of autoimmune diseases in relatives of MMN patients and controls

\begin{tabular}{|c|c|c|c|}
\hline Disease & $\begin{array}{l}\text { Prevalence }(\%) \\
\text { relatives MMN } \\
\text { patients } \\
(n=417)\end{array}$ & $\begin{array}{l}\text { Prevalence }(\%) \\
\text { relatives } \\
\text { controls } \\
(n=2377)\end{array}$ & $p$ value \\
\hline Diabetes type 1 & 1.2 & 0.2 & 0.002 \\
\hline $\begin{array}{l}\text { Graves' } \\
\text { hyperthyroidism }\end{array}$ & 0.7 & 0.8 & n.s \\
\hline $\begin{array}{l}\text { Hashimoto's thyroid } \\
\text { disease }\end{array}$ & 1.4 & 0.5 & 0.01 \\
\hline Addison's disease & 0 & 0 & n.s \\
\hline Rheumatoid arthritis & 1.9 & 1.9 & n.s \\
\hline Ankylosing spondylitis & 0.7 & 0.3 & n.s \\
\hline $\begin{array}{l}\text { Systemic lupus } \\
\text { erythematosus }\end{array}$ & 0 & 0 & n.s \\
\hline $\begin{array}{l}\text { Cutaneous lupus } \\
\text { erythematosus }\end{array}$ & 0 & 0 & n.s \\
\hline Sjögren's syndrome & 0 & 0 & n.s \\
\hline Myasthenia gravis & 0 & 0.1 & n.s \\
\hline Multiple sclerosis & 0.2 & 0.4 & n.s \\
\hline Dermatomyositis & 0 & 0.04 & n.s \\
\hline Psoriasis & 1.9 & 1.4 & n.s \\
\hline Vitiligo & 0.7 & 0.2 & n.s \\
\hline Crohn's disease & 0 & 0.6 & n.s \\
\hline Ulcerative colitis & 0 & 0.3 & n.s \\
\hline Celiac disease & 0.2 & 0 & 0.02 \\
\hline Pernicious anaemia & 0 & 0.1 & n.s \\
\hline
\end{tabular}

that patients with MMN may have an increased risk for AID, and that MMN may share common pathogenic mechanisms such as genetic background, environmental triggers and/or changed immune homeostasis with AID $[7,9]$.

The main strengths of this study are the relatively large number of included patients with this rare neuropathy and the inclusion of relatively large numbers of gender-matched controls. Baseline characteristics of patients and controls were comparable except for age at inclusion, which was significantly higher in the control group (median age 55 versus 60 years). Recall bias or bias introduced by differences in response rates are unlikely, given the comparable prevalence of asthma and myocardial infarction in patients and controls. The prevalence of AID in controls was within the estimated range $(5-9.4 \%)$ of the Dutch Central Bureau for Statistics.

Although the Dutch MMN patient cohort is relatively large, the main limitation of this study remains its power [6]. The study is clearly underpowered to detect associations of specific AID with MMN due to the rarity of both MMN and AID. In view of the association with elevated serum levels of anti-GM1 IgM antibodies, we hypothesized 
that B-cell dysfunction is an important underlying pathogenic mechanism in MMN. There was no co-segregation of mainly B-cell-mediated AID such as myasthenia gravis and systemic lupus erythematosus with MMN. We previously found that HLA-DRB $1 * 15$ is more prevalent among patients with MMN than in population based controls [15] similar to patients with MS [13]. However, none of the MMN patients and only one relative of a MMN patient had MS. Importantly, the numbers of patients and controls are too small to draw definite conclusions or to exclude an association of B-cell-mediated AID or MS. Although the use of questionnaires may increase the risk of ascertainment bias, we feel this is unlikely. Telephone interviews were conducted to confirm the validity of reported diagnoses. The accuracy of reported diagnoses was also confirmed by the information (correspondence from medical specialists other than neurologists) available in patient files. We also chose to include only first-degree relatives to reduce the risk of including hearsay diagnoses in secondand third-degree relatives.

Frequencies of diabetes type 1, Hashimoto's thyroid disease, and celiac disease were significantly increased among first-degree relatives of MMN patients as compared to controls. Celiac disease and Hashimoto's thyroid disease were also more frequent in patients with MMN than controls. Anti-ganglioside antibodies have also been reported in patients with celiac disease [2, 3]. One patient with MMN and celiac disease had anti-GM1 IgM antibodies, but the other did not. Although the data about the autoimmune diseases should be interpreted with great care due to the small numbers, it is interesting to note that both type 1 diabetes and celiac disease $[14,21]$, and type 1 diabetes and Hashimoto's thyroid disease $[16,21]$ co-segregate. MMN susceptibility may therefore be determined by genetic variants that are associated with these clusters, in addition to HLADRB $1 * 15$ [15].

The risk of additional AID was highest in female patients with MMN. This finding, combined with the predominance of men with MMN, may suggest gender differences in factors that determine susceptibility. Such differences have been identified previously in patients with other inflammatory neuropathies [10]. In concordance with the findings in control populations, the family histories of MMN patients show a predominance of women with an AID. Unlike the findings in LEMS and MG we found no specific maternal transmission pattern of AID in patients with MMN [8, 20].

Our data suggest that the frequency of additional AID is increased in patients with MMN. Studies with a larger sample size to ensure sufficient power are needed to detect associations with specific AID that could help to identify shared risk factors.

\section{Conflict of interest None.}

Open Access This article is distributed under the terms of the Creative Commons Attribution Noncommercial License which permits any noncommercial use, distribution, and reproduction in any medium, provided the original author(s) and source are credited.

\section{References}

1. Diabetes epidemiology research international group (1987) Preventing insulin dependent diabetes mellitus: the environmental challenge. Br Med J (Clin Res Ed) 295:479-481

2. Alaedini A, Green PH, Sander HW, Hays AP, Gamboa ET, Fasano A, Sonnenberg M, Lewis LD, Latov N (2002) Ganglioside reactive antibodies in the neuropathy associated with celiac disease. J Neuroimmunol 127:145-148

3. Briani C, Zara G, Toffanin E, Ruggero S, Ferrarini A, De LF, Luca M, Faggian D, Grassivaro F, Ermani M, Pezzani R, Giometto B, D'Odorico A (2005) Neurological complications of celiac disease and autoimmune mechanisms: preliminary data of a prospective study in adult patients. Ann NY Acad Sci 1051:148-155

4. Broadley SA, Deans J, Sawcer SJ, Clayton D, Compston DA (2000) Autoimmune disease in first-degree relatives of patients with multiple sclerosis: a UK survey. Brain 123(Pt 6):1102-1111

5. Cats EA, Jacobs BC, Yuki N, Tio-Gillen AP, Piepers S, Franssen H, Van Asseldonk JT, Van den Berg LH, van der Pol WL (2010) Multifocal motor neuropathy: association of anti-GM1 IgM antibodies with clinical features. Neurology 75:1961-1967

6. Cats EA, van der Pol WL, Piepers S, Franssen H, Jacobs BC, Van den Berg-Vos RM, Kuks JB, van Doorn PA, van Engelen BG, Verschuuren JJ, Wokke JH, Veldink JH, Van den Berg LH (2010) Correlates of outcome and response to IVIg in 88 patients with multifocal motor neuropathy. Neurology 75:818-825

7. Cooper GS, Bynum ML, Somers EC (2009) Recent insights in the epidemiology of autoimmune diseases: improved prevalence estimates and understanding of clustering of diseases. J Autoimmun 33:197-207

8. Drachman DB (1994) Myasthenia gravis. N Engl J Med 330:1797-1810

9. Langer-Gould A, Albers KB, Van Den Eeden SK, Nelson LM (2010) Autoimmune diseases prior to the diagnosis of multiple sclerosis: a population-based case-control study. Mult Scler 16:855-861

10. McCombe PA, Csurhes PA, Greer JM (2006) Studies of HLA associations in male and female patients with Guillain-Barre syndrome (GBS) and chronic inflammatory demyelinating polyradiculoneuropathy (CIDP). J Neuroimmunol 180:172-177

11. Parry GJ, Clarke S (1988) Multifocal acquired demyelinating neuropathy masquerading as motor neuron disease. Muscle Nerve 11:103-107

12. Pestronk A, Cornblath DR, Ilyas AA, Baba H, Quarles RH, Griffin JW, Alderson K, Adams RN (1988) A treatable multifocal motor neuropathy with antibodies to GM1 ganglioside. Ann Neurol 24:73-78

13. Schmidt H, Williamson D, Ashley-Koch A (2007) HLA-DR15 haplotype and multiple sclerosis: a HuGE review. Am J Epidemiol 165:1097-1109

14. Smyth DJ, Plagnol V, Walker NM, Cooper JD, Downes K, Yang JH, Howson JM, Stevens H, McManus R, Wijmenga C, Heap GA, Dubois PC, Clayton DG, Hunt KA, van Heel DA, Todd JA (2008) Shared and distinct genetic variants in type 1 diabetes and celiac disease. N Engl J Med 359:2767-2777 
15. Sutedja NA, Otten HG, Cats EA, Piepers S, Veldink JH, van der Pol WL, Van den Berg LH (2010) Increased frequency of HLADRB1*15 in patients with multifocal motor neuropathy. Neurology $74: 828-832$

16. Umpierrez GE, Latif KA, Murphy MB, Lambeth HC, Stentz F, Bush A, Kitabchi AE (2003) Thyroid dysfunction in patients with type 1 diabetes: a longitudinal study. Diabetes Care 26:1181-1185

17. Van den Berg-Vos RM, Franssen H, Wokke JH, Van Es HW, Van den Berg LH (2000) Multifocal motor neuropathy: diagnostic criteria that predict the response to immunoglobulin treatment. Ann Neurol 48:919-926

18. van Es MA, van Vught PW, Blauw HM, Franke L, Saris CG, Andersen PM, Van den Bosch L, de Jong SW, van't Silot R, Birve A, Lemmens R, de Jong V, Baas F, Schelhaas HJ, Sleegers
K, Van Broeckhoven C, Wokke JH, Wijmenga C, Robberecht W, Veldink JH, Ophoff RA, Van den Berg LH (2007) ITPR2 as a susceptibility gene in sporadic amyotrophic lateral sclerosis: a genome-wide association study. Lancet Neurol 6:869-877

19. Willison HJ, Yuki N (2002) Peripheral neuropathies and antiglycolipid antibodies. Brain 125:2591-2625

20. Wirtz PW, Bradshaw J, Wintzen AR, Verschuuren JJ (2004) Associated autoimmune diseases in patients with the LambertEaton myasthenic syndrome and their families. J Neurol 251:1255-1259

21. Zhernakova A, van Diemen CC, Wijmenga C (2009) Detecting shared pathogenesis from the shared genetics of immune-related diseases. Nat Rev Genet 10:43-55 